45 (1) | 2016

En el río del Maíz (Madre de Dios)

Homenaje a Bernard Lelong

\title{
Los espíritus-jaguares: cráneos-trofeos y chamanismo entre los mojos (siglo XVII)
}

Les esprits-jaguars : crânes-trophées et chamanisme chez les Mojos (XVII

siècle)

The jaguars-spirits: skull-trophies and shamanism among the Mojos (17 th

century)

Vincent Hirtzel

\section{(2) OpenEdition}

Journals

Edición electrónica

URL: http://journals.openedition.org/bifea/7950

DOI: $10.4000 /$ bifea. 7950

ISSN: 2076-5827

Editor

Institut Français d'Études Andines

Edición impresa

Fecha de publicación: 1 abril 2016

Paginación: 227-252

ISSN: 0303-7495

\section{Referencia electrónica}

Vincent Hirtzel, « Los espíritus-jaguares: cráneos-trofeos y chamanismo entre los mojos (siglo XVII) », Bulletin de l'Institut français d'études andines [En línea], 45 (1) | 2016, Publicado el 08 abril 2016, consultado el 05 noviembre 2020. URL : http://journals.openedition.org/bifea/7950; DOI : https:// doi.org/10.4000/bifea.7950

\section{(c) (i) $\odot$}

Les contenus du Bulletin de l'Institut français d'études andines sont mis à disposition selon les termes de la licence Creative Commons Attribution - Pas d'Utilisation Commerciale - Pas de Modification 4.0 International. 


\title{
Los espíritus-jaguares: cráneos-trofeos y chamanismo entre los mojos (siglo XVII)*
}

\author{
Vincent Hirtzel**
}

\section{Resumen}

La caza de cabezas realizada por los mojos de los llanos del Oriente boliviano antes de su reducción por los jesuitas (fines del siglo XVII) tenía una particularidad única sobre el continente sudamericano: asociaba tanto cráneos-trofeos humanos como cráneos-trofeos de jaguares. Este artículo reexamina las fuentes jesuitas relativas a estas prácticas en su conjunto. Basándose en los contrastes y las semejanzas de la etnografía moja en relación a otros casos de caza de trofeos mejor conocidos de las tierrasbajas (Amazonía, Gran Chaco) por un lado, sacando provecho de la etnografía moderna de grupos vecinos (chimanes y yurakarés) por el otro, muestra que esta asociación es indisociable de un complejo chamánico particular donde el jaguar tiene un papel de primer plano. Entre los mojos, este felino adquirió el estatus de un espíritu sui generis: es el único que presenta un cuerpo públicamente visible.

Palabras clave: mojos, cabezas-trofeos, chamanismo, guerra indígena, cacería, etnografía jesuita

\section{Les esprits-jaguars : crânes-trophées et chamanisme chez les Mojos (XVII ${ }^{m e}$ siècle)}

\section{Résumé}

La chasse aux têtes réalisée par les Mojos des savanes de l'Orient bolivien avant leur concentration dans les missions jésuites (fin du XVII ${ }^{\mathrm{e}}$ siècle) avait pour particularité, unique sur le continent sudaméricain, d'associer la production de crânes-trophées humains à celle de crânes-trophées de jaguars.

Este artículo presenta una parte de los resultados de un proyecto de investigación posdoctoral titulado « L'entrelacs des points de vue: essai d'anthropologie et d'histoire en Amazonie bolivienne » financiado por el Legs Lelong en 2012.

** CNRS, UMR 7186 LESC-EREA. Maison Archéologie \& Ethnologie René-Ginouvès, 21, allée de I'université 92023 Nanterre cedex. E-mail: hirtzel@hotmail.com 
Cet article se propose de réexaminer les sources jésuites concernant ces pratiques dans leur globalité. Se fondant sur les contrastes et les similitudes que celles-ci présentent avec d'autres cas de chasse aux trophées mieux connus des basses-terres (Amazonie, Chaco), tout en mettant à profit l'ethnographie moderne de groupes voisins (Chimane et Yurakaré), il entend montrer que ce couplage est inséparable d'un complexe chamanique particulier où le jaguar joue un rôle de premier plan. Au sein des Mojos, ce félin a acquis le statut d'un esprit sui generis : il est le seul à présenter un corps publiquement visible.

Mots-clés : Mojos, têtes-trophées, chamanisme, guerre indigène, chasse, ethnographie jésuite

\title{
The jaguars-spirits: skull-trophies and shamanism among the Mojos (17 $7^{\text {th }}$ century)
}

\begin{abstract}
Head-hunting realized by the Mojos of the eastern Savannah of Bolivia, before their concentration in the Jesuit missions at the end of the $17^{\text {th }}$ century had a peculiarity unique on the South American continent. It associated the skull-trophies of human beings with the skull-trophies of jaguars. This article offers a new examination of the Jesuit sources concerning these practices as a whole. Based upon the contrasts and the similarities of the Mojos' ethnography with others, better known, cases of trophy-hunting in the eastern lowlands (Amazonia, Gran Chaco) and taking advantage of the modern ethnography of nearby groups (Chimane and Yurakaré), it shows that this coupling is embedded in a particular shamanic complex where the jaguar plays a leading role. Among the Mojos, this feline acquired the status of a sui generis spirit, unique in its capacity of displaying a publicly visible body.
\end{abstract}

Key-words: Mojos, head trophies, shamanism, indigenous war, hunting, Jesuit ethnography

A partir del último tercio del siglo XVII, los jesuitas empezaron a desplegarse en los llanos de las tierras-bajas de la Bolivia actual. Al cabo de una quincena de años, lograron convencer a los rivereños de habla arawak del río Mamoré, donde se instalaron al inicio, de conformar sus primeras misiones (Loreto 1684, Santísima Trinidad 1687). Se instalaron después éxitosamente en las sabanas que se expanden al este del Mamoré donde otra población de lengua cercana a la primera, ocupaba la región. Con ella los jesuitas fundaron San Ignacio (1689), luego, con la misma y otros grupos (de lenguas no arawak), San José (1691). Estos dos grupos arawak, que para seguir la tradición acuñada por los jesuitas, seguiremos llamando aquí mojos¹, compartían una práctica desconcertante para los religiosos: en la casa colectiva erguida en el centro de sus pueblos, colgaban y conservaban calaveras humanas y cráneos de jaguares. Los trofeos humanos eran

1 Los jesuitas retomaron este nombre, ya asociado anteriormente por los habitantes de Santa Cruz de la Sierra con los habitantes del Mamoré. No se trata de una autodenominación. Los jesuitas hubieran podido llamarlos achanés, palabra significando en su idioma «personas, gente». Los cognados de esta palabra sirvieron algunas veces para forjar etnónimos: chanés de la Cordillera quienes fusionaron con los guaraníes inmigrados desde el río de la Plata; chanés del Pantanal, mejor conocidos como guanas o, actualmente terenas. La misma raíz se encuentra también en a-shani-nka, yane-sha, yinee (piros), en el Perú. Para la distinción entre «arawak ribereños» y «arawak llaneros» ver Hirtzel \& Daillant (2012). 
relativamente escasos, los de felinos, en cambio, numerosos (Del Castillo, 1906 [ca. 1676]: 328). Tal exhibición de reliquias óseas en el centro de sociabilidad colectiva no tenía nada para complacer a los jesuitas: les pareció abyecta y vil, testimonio material de la perversidad que cultivaba el diablo para hacerse adorar por los hombres. Cuando sintieron que estaban en las condiciones de hacerlo, empezaron por inmolar públicamente estos impíos objetos por el fuego (Eguiluz, 1884 [1696]: 29) y, después, con más suavidad tal vez, los hundieron en el río, siguiendo así la solicitud de sus dueños (Altamirano, 1979 [1712]: 62-63).

Apremiados por la urgencia de su «misión», los jesuitas acordaban un interés limitado a las prácticas culturales de la gente que tenían que convertir y les bastaba tener de estas una visión general. Después de haber sido testigos de los rituales por los cuales las calaveras de jaguares eran «consagradas», se convencieron de que se trataba de una manifestación concreta de idolatría — «entre ellos casi la única idolatria exterior» (Eguiluz, 1884 [1696]: 29) — mediante la cual los mojos honraban a un (falso) dios: el dios-jaguar (alias del diablo). Como no tuvieron la oportunidad de presenciar conflictos guerreros y decapitaciones de enemigos, avanzaron la tesis (y probablemente dedujeron) que la producción de trofeos humanos seguía la misma lógica: las «calaveras humanas de los que habian muerto en sus guerras [...] se consagraban al dios presidente de ellas» (Eguiluz, 1884 [1696]: 17) un «dios de las guerras» tan enigmático como demoníaco. Tales conclusiones deficientes desde el punto de vista antropológico parecen más útiles para estudiar los prejuicios de los convertidores que para entender las prácticas de los convertidos. Sin embargo, sería erróneo tildarlas de absurdas. Las observaciones etnográficas que los jesuitas han consignado muestran, en todo caso, por qué han optado por esta interpretación. Es a una nueva exploración de estos datos que el presente texto se consagrará, buscando a la vez entender porque los jesuitas consideraron estos trofeos como soportes de «idolatría» así como para ir más allá de su punto de vista.

La relectura de las fuentes jesuitas sobre los mojos es un tema clásico de los estudios históricos bolivianos y su contenido propiamente etnográfico ha sido examinado varias veces empezando por Alfred Métraux (1942; 2013 [1943])2. Posteriormente muchos investigadores, en Bolivia o en otras partes, se han interesado en la etnografía de los mojos antes de la reducción, con una perspectiva arqueológica (Denevan 1980 [1966]), histórica (Block, 1997 [1994]), o haciendo dialogar el pasado con la etnografía contemporánea como en los trabajos de Zulema Lehm Ardaya (1998; 2015 [1999]). Más recientemente se han proporcionado nuevas síntesis (Cortés Rodríguez, 2005), catalogado sistemáticamente las fuentes relevantes (Ribera

2 Métraux fue el primero en proporcionar una síntesis de la mayoría de las fuentes pertinentes pero es necesario precisar que, a veces, incurre en simplificaciones engañosas. Cuando trata del «chamanismo mojo», por ejemplo, no duda en fusionar los datos de los dos grupos considerados en este texto con los que son relativos a los más lejanos baures, también de idioma arawak y reducido por los jesuitas. Si bien es claro que existen elementos en común entre estos grupos, no se puede asimilar sin evaluación crítica la información en procedencia de los baures. Este punto es particularmente válido en cuanto a la temática de los trofeos: los baures, como lo indican las fuentes, nunca han conservado calaveras ni de humanos, ni de jaguares. 
Paniagua, 2009) y trabajado varios temas etnohistóricos sobre los cambios sociales generados en las misiones. En esta línea de investigación, destacan los trabajos de Akira Saito sobre la apropiación de la escritura por los mojos (2005) o, más recientemente, sobre la transformación de la guerra en contexto misional (2015).

Sin embargo, a pesar del interés nutrido que ha generado la etnografía jesuita, ningún investigador se ha concentrado hasta la fecha sobre el complejo prereduccional de sus trofeos, aprovechando así la oportunidad de examinarlo con el trasfondo de la abundante literatura antropológica que se ha dedicado a este tipo de reliquias en las tierras bajas sudamericanas. Las calaveras que conservaban los mojos forman parte de un conjunto de trofeos de guerra no muy frecuentes o generalizados en esta amplia región, pero tampoco excepcionales. Pueden ser comparadas con las cabezas reducidas por los grupos jívaros (Taylor 1985; 1993), las cabezas momificadas mundurukús (Menget, 1996), los scalps en el Chaco (Sterpin, 1993); los cráneos y/o dientes montados en collares donde los yaguas (Chaumeil, 1985) o donde sus vecinos mirañas (Karadimas, 1999), para citar los ejemplos más relevantes. La oportunidad de retomar el estudio de los trofeos mojos se vuelve aún más alentadora, ya que hoy en día la etnografía regional es mejor conocida gracias a los trabajos consagrados a los chimanes y a los yurakarés (Daillant, 1998; 2003; Djup, 2007; Hirtzel, 2010); dos grupos que hablan lenguas aisladas o casi (el chimane tiene por única lengua «hermana»al mosetén) cuyos antepasados eran vecinos directos de los mojos que producían estos trofeos.

Al ubicar los cráneos-trofeos mojos en tal ámbito comparativo, este trabajo no tiene por único afán contribuir a un aggiornamento necesario. Además de actualizar la hermenéutica de las fuentes, busca también identificar algunas especificidades en el material mojo susceptibles de retroalimentar el estudio de los trofeos en general. Dada la casi ausencia de registros tanto etnográficos como históricos, y al parecer arqueológicos, de una producción conjunta de cráneos humanos y jaguares, una pregunta se impone: ipor qué les gustaba tanto a los mojos acumular trofeos de jaguares? ¿Qué estatus tenía el jaguar para poder ser sistemáticamente objeto de tal tratamiento? Queremos sugerir en este texto que el rendimiento particular del jaguar como trofeo no dependía del hecho de que el felino haya sido una simple «variante combinatoria» de un enemigo humano. Si la posibilidad de considerar calaveras humanas y calaveras de jaguares como «intercambiables» hubiera sido tan obvia, su frecuencia hubiera tenido que ser mucho más elevada en las tierras bajas suramericanas. Paradójicamente, el único animal del cual se producía sistemáticamente cabezas trofeos era, entre los jívaros, el perezoso (Karsten, 2000 [1935]: 227-228). Veremos en las páginas siguientes que lo que es decisivo en el caso mojo, es, por un lado, la intrincación de la producción de estos dos trofeos en un complejo chamánico con rasgos singulares, y, por el otro, la potencialización de ciertas interacciones con los jaguares que permitió a los mojos asimilarlos a una clase sui generis de espíritu. 


\section{ENTRE ATAQUES Y CONTRAATAQUES}

La producción de trofeos de jaguares no puede ser aprehendida sin ser considerada en la trama de relaciones que mantenían los mojos con los jaguares, entendidos aquí simplemente como fieras: fieras que pueden atacar humanos o pueden ser matados por humanos. Este régimen de interacción predador stricto sensu aparece comentado comúnmente y de varias formas en los textos que nos han dejado los jesuitas, marcando así la pauta de la situación. Nos enseñan que, por su cantidad y su ferocidad, los jaguares, llamados ichini por los mojos, eran particularmente temidos. Uno de ellos advierte que se encontraban en «abundancia en los montes y pampas», añadiendo que los mojos eran «muchas veces acometidos, y aun mordidos y muertos de tigres», en particular cuando salían de cacería o estaban de viaje, puesto que dormían «siempre en los suelos, sin rresguardo ni centinela» (Orellana, 1906 [1687]: 8). Otro afirma que el «tigre en todas partes acomete y a veces entra de noche a los pueblos, sin que haya lugar seguro de sus garras.» (Anónimo, 2005 [1754]: 106).

A la luz de tales observaciones, los jesuitas no dudaron en proponer una explicación psicológica al «culto» de los cráneos y a derivarlo del miedo que les infundía y a los estragos que causaba.

[Los jaguares] eran los que tenían más culto exterior, por el gran terror de aquellas fieras de que abunda aquella tierra, de suerte que son muchos los indios que perecen en sus garras (Altamirano, 1979 [1712]: 31).

Sabiendo que este culto era por otra parte el producto de las artimañas del diablo, resultaba lógico que los misioneros puedan pensar que, debido a su propia presencia y a los avances del proceso de conversión, cambie la relación de los mojos con los jaguares:

Otro es acerca de los tigres, que siendo como dije tantos los que mordía esta fiera y los que mataba, ya bautizados no ha mordido á ninguno, casi seis años, porque en sus dormidas ponen por atalaya la santa cruz, que dicen los defienden; y así se valen de ella en todos los peligros (Orellana, 1906 [1687]: 20).

La providencia podía explicar tales «milagros» para los misioneros; para los mojos, en cambio, atribuir a la cruz el poder de repeler a los jaguares, mostraba que dotaban las parafernalias de sus conversores de facultades «chamánicas» de las cuales no querían privarse. No hay razón de pensar, por supuesto, que los jaguares viviendo en el territorio de los mojos eran más antropófagos que en otras partes. Un jesuita, incluso lo reconoce:

[S]on feroces en grandeza y braveza, bien que poco cebados en la gente, rara desgracia se cuenta (Del Castillo, 1906 [ca. 1676]: 305).

Entre las exageraciones de un jaguar omnipresente y diabólico y las de un jaguar ausente neutralizado por el bautismo, vale la pena notar que algunos factores han podido favorecer el interés particular que los mojos han dirigido hacia el animal o, al menos, darle una inflexión particular, distinta a otras partes de la Amazonía. 
Durante la temporada de lluvias, importantes superficies de los llanos de Mojos son frecuentemente inundadas. Los mamíferos tienden entonces a refugiarse sobre lomas o terraplenes cubiertos de monte. De origen antrópico estas elevaciones fueron progresivamente edificadas durante un milenio (entre 400-1400 d. C.) en articulación con la apertura de canales (Lombardo \& Prümers, 2010). No sabemos si estas obras de tierra fueron creadas con la intención de un manejo consciente de la fauna, tanto de las presas como de los predadores. En todo caso, incluso después de que la «cultura hidráulica» de la región haya perdido mucho de su lustre, no dejaban estos lugares de producir efectos. En el siglo XIX, en una época que sobre este punto era similar al siglo XVII, Alcide d'Orbigny notaba a propósito de ellos:

Ocurre demasiado a menudo que los jaguares, huyendo la inundación general, vayan buscar ahí [...] una presa más fácil [...]. Esta circunstancia hace de tales parajes, lugares poco seguros para los Indios; desprovistos de armas para defenderse, no los abordan solos (D'Orbigny, 1844: 101, trad. nuestra).

Las lomas favorecían la concentración territorial cíclica de los animales. Se incrementaba así la probabilidad de encuentros con los jaguares, pero también la posibilidad para los humanos de actuar como ellos. A semejanza del jaguar, aprovechaban también los mojos la concentración de presas en estas islas para organizar cazas colectivas (al parecer náuticas)3.

Por las razones expuestas arriba, los jesuitas enfatizaron el hecho de que los mojos eran presas de los jaguares. Pero sería un error pensar que estos eran totalmente indefensos. Sabían protegerse de él con medios pragmáticos más eficientes que cruces (explotando su antipatía por el fuego y la luz en un ambiente nocturno) y tampoco dudaban en cazarlo. Muy frecuentemente, los jaguares eran matados en cazas «defensivas»; estas cazas portaban sobre individuos furtivos y oportunistas, merodeando en los alrededores de los pueblos, a proximidad de la gente en desplazamiento o en excursión de casería.

El modo de librarse de él, cuando duermen fuera de poblado, es encender hogueras, porque se ha experimentado tienen mucho miedo al fuego y con un mechón encendido y con un tizón los persiguen y ahuyentan; para desalojarlo de las cercanías de los pueblos y librarse de los daños que hace allí emboscado, se valen de perros rastreros, que lo descubren por el olfato y, ya montado el tigre a algún árbol, lo matan con flechas hechas a este propósito, del tamaño y forma de unos rejones 4 . Suelen también armarle

3 «[A] veces se juntan a un lugar para montería: entonces cercan el monte, unos con los arcos templados y a punto las flechas, y otros entran a [i...?] con perros y voces; este modo de montería es mas a proposito cuando está toda la campaña inundada y se ha recogido la caza a sitios altos: entonces cercan el sitio con canoas y allí van [f. 12] flechando las que espantan para afuera los batidores y juegan [?] con tanta velocidad las canoas con palancas en vez de remos, que siguen y dan caza hasta [a] los gamos» (Anónimo, 2005 [1754]: 106).

4 La técnica es confirmada por otras fuentes: «encuentran [el jaguar] en el monte, con los perros le obligan á ganar un árbol y allí lo flechan» (Del Castillo, 1906 [ca. 1676]: 316). 
trampas por el camino por donde ha de pasar a acabar de comer la presa comenzada: cavan un foso profundo y lo cubren de hojas y ramazones débiles y, al pasar, se precipita, quedando en el hoyo muchas veces atravesado de agudas y largas puntas de chontas ${ }^{5}$, que afirman en el centro o suelo del hoyo (Anónimo, 2005 [1754]: 106).

Además de las técnicas de eliminación de los jaguares que se aproximaban a sus lugares de vida, con ayuda de sabuesos o de trampas, los mojos organizaban cazas colectivas que denotan un aspecto más ofensivo y bélico, implicando, por otra parte, un registro particular de comunicación con el animal: no se trataba de hacerlo huir con luz, pero de engañar su oído en la oscuridad. Esta técnica consistía en acercarse de noche por río hasta el lugar donde se presumía que se encontraba el animal. Para atraerlo, se tocaba luego un instrumento constituido por una calabaza o mate, produciendo un sonido comparable a su rugido. Los cazadores, invisibles por el jaguar, se hacían escuchar, comunicando en su «idioma», le hacían creer en la presencia de un congénere. Cuando aparecía el jaguar, era brutalmente atacado a flechazos y saetazos en un enfrentamiento a veces espectacular.

Delante de mí flecharon dos canoas á uno y con más de seis saetas en el cuerpo revolvió para la ribera, era disforme, yo estaba en una canoa y cuando llegó cerca de la orilla se revolcó, quebró unas despidió sacudiéndose otras y bramando saltó á ganar la barranca; volaron otras de nuevo, unas se emplearon en su cuerpo, otras se clavaron en los palos del monte. Los indios esperaron un gran rato, ciertos de que ya llevaba bastante recado, siguieron después el rastro de la sangre, seguílos con un alfangillo en las manos: hallábamos rastros de sangre donde se había recostado y todo el camino que llevaba regado de ella; pero él se entro tan adentro á morir que cansados volvimos (Del Castillo, 1906 [ca. 1876]: 315-316).

La posibilidad de coordinar de manera colectiva tales cacerías de jaguar parece adecuarse relativamente bien con la existencia de las lomas antrópicas mencionadas previamente. En tiempo de agua, un jaguar atraído por grandes mamíferos en una zona de altura, si no era «preso» en esta isla, resultaba fácil de ubicar, dando también el tiempo a sus enemigos humanos de preparar un ataque que, por lo tanto, podía asemejarse a un asalto guerrero planificado.

\section{TROFEOS}

Hubiera sido de mucho interés saber si, por un lado, todos los jaguares matados por los mojos servían a la producción de trofeos y, por el otro, si cualquier jaguar era considerado como un trofeo potencial. No se ha podido encontrar ninguna información sobre estos puntos. Las fuentes, sin embargo, dan la impresión de que

5 Palabra regional (de origen quechua) usada para varias especies de palmeras como Astrocaryum spp. y Bactris gasipaes. 
la producción de trofeos era sistemática y los rituales que seguían su matanza, por su rigor y elaboración, tienden a confirmarlo. Los «jaguaricidas» eran apartados un tiempo de sus familiares y se sometían a diversas prohibiciones idénticas a las que se encuentran en todas las fases del tratamiento poshomicidio documentadas en la Amazonía, que estas estén o no acompañadas por la fabricación de trofeos. Aparentemente, el cadáver del felino no era despedazado en el lugar de su muerte, sino llevado cerca del pueblo. Por miedo a las enfermedades que podía generar, quedaba en los alrededores. A propósito de un jaguar depositado en una playa del río Mamoré, los misioneros notaron que

[Los mojos] no lo quisieron meter dentro del pueblo, porque dijeron que luego se llenarían de cóleras (Marbán et al., 1898 [1676]: 154).

La cercanía de un río era necesaria para la elección del lugar donde el animal iba a ser despedazado: se requería agua tanto para el tratamiento de los matadores como del despojo.

El retorno o la llegada de los cazadores con el cuerpo del jaguar era un evento celebrado con música; los habitantes de la comunidad se reunían con los cazadores que llevaban el cadáver con tambores y otros instrumentos. Este concierto podía también acompañar el transporte del jaguar, por ejemplo si era matado en una trampa. Los jesuitas han podido considerar este acompañamiento colectivo y musical como un bullicioso «triunfo» (Anónimo, 2005 [1754]: 108). Estas dimensiones de regocijo musical posmatanza hacen echo a las salidas para la guerra (como a los retornos victoriosos) de los mojos (Del Castillo, 1906 [ca. 1676]: 341). En estas ocasiones también se tocaba un «pequeño tambor» y flautas; estas últimas pudiendo estar confeccionadas «de canillas de enemigos que en otras batallas habían muerto; y a falta de éstas, de una ala de casipí pájaro parecido a la grulla.» (Anónimo, 2005 [1754]: 111).

Donde el cadáver del jaguar yacía, se llevaban a cabo diversos rituales cuyos protagonistas esenciales eran, por lo menos inicialmente, las mujeres del pueblo, es decir parientes de los matadores. La descripción que tenemos de esta fase es poco detallada y solo sabemos que una de estas mujeres se acercaba al cadáver y quebraba una olla, después un grupo de mujeres se ponía a bailar (Del Castillo, 1906 [ca. 1676]: 359). Solo los cazadores podían mantener un contacto físico con el despojo; eran por lo tanto ellos que se encargaban de cortarlo. Después de la acogida femenina, el animal era desollado y su pellejo tendido y puesto a secar al sol (Del Castillo, 1906 [ca. 1676]: 359). Según el mismo misionero no era imposible que pedazos del jaguar hubiesen entonces sido ingeridos: «dicen que lo comen, no lo he visto» (Del Castillo, 1906 [ca. 1676]: 359). Aunque la información no haya sido consignada en papel, podemos suponer que el cráneo (y los huesos) eran limpiados y separados de todo resto de carne después de cocción. Que esta fase haya podido coincidir con la absorción (probablemente en pequeña cantidad)

6 La palabra casipi se refiere a dos especies de aves zancudas de la familia de los Ciconiidae, conocidos hoy en el Oriente boliviano como el bato (Jabiru mycteria) y la cabeza seca (Mycteria americana) (Ver Ott \& Burke de Ott, 1983: 124). 
de jaguar cocido, no tendría nada de sorprendente ${ }^{7}$ Luego del cuarteamiento, las mujeres lavaban los cazadores y los pintaban de negro (Del Castillo, 1906 [ca. 1676]: 359) es decir con bí (Genipa americana), dos operaciones corrientes en Amazonía para el tratamiento poshomicidio.

Probablemente durante el tiempo que esta pintura era visible (unos diez días), los «jaguaricidos» eran recluidos en la céntrica casa colectiva del pueblo designada a menudo como «bebedero» (bomope en mojo) 8 . Al parecer las prohibiciones que se imponían eran esencialmente de orden alimenticias y sexuales. Lamentablemente los jesuitas describen los «ayunos» (para usar su palabra), sobre un modo general y no sabemos nada de sus posibles diferencias aunque hayan notado que no son todos iguales (Del Castillo, 1906 [ca. 1676]: 355). Cuando «ayunaban», los mojos no paraban de comer, sino que disminuían la cantidad de calorías ingeridas, suprimían el uso de condimentos estimuladores de las percepciones gustativas (la sal y el ajî); además comían en la noche, quedándose todo el día con el estómago vacío. Se sorprendieron en todo caso los jesuitas tanto de la multiplicación de ocasiones acarreando tales precauciones, como de la seriedad con la cual los mojos se sometían a ellas: «no quebrantarán rito ni ayuno por cuanto tiene el mundo.» (Del Castillo, 1906 [ca. 1676]: 358).

Las fuentes son mudas sobre la preparación de las reliquias y las circunstancias durante las cuales eran instaladas en la casa colectiva. La introducción de los trofeos era sin duda festejada colectivamente y no un acto individual o trivial. Es muy posible que un jesuita aluda a los complejos rituales cumplidos entonces cuando nota, a propósito del jaguar, que «hacían anatomía de el, dividiendo todos los huesos, poniéndolos en fila y, delante, la piel de la cabeza sobre un palo levantado y alre[de]dor bebían, cantaban y bailaban.» (Anónimo, 2005 [1754]: 108). Las calaveras, tanto de jaguar como de humano, no eran colgadas «desnudas» pero adornadas y refaccionadas: «sacan la calavera munda, pónenle pábilo como quedejas.» Estas mechas podían ser tintas y daban al cráneo la apariencia de «cabellera de algodon de varios colores» (Eguiluz, 1884 [1696]: 29). Los cráneos humanos, por su parte, recibían ojos postizos, como lo indica la mención (hasta hoy inédita) siguiente:

A las calaberas humanas les ponen cabelleras de algodón y en las cuencas de los ojos unas conchas, y por niñas unos frijoles colorados (Soto, 1668: f. ${ }^{\circ} 136 r$.).

Ninguna fuente indica que los mojos quitaban los dientes de sus víctimas tanto humanas como felinas al preparar los trofeos, como era el caso en el Alto

7 Este tipo de canibalismo «de limpieza» acompaña la producción de los scalps en el Chaco (Sterpin, 1993).

8 Un jesuita indica que los matadores tenían que «estar algunos días en el bebedero sin entrar en su casa» (Orellana, 1906 [1687]: 9). La designación de estas casas como «bebedero» se debe probablemente al hecho de que se encontraban depositados ahí cántaros de chicha. No se trata de una invención terminológica jesuita. Su uso remonta a las expediciones militares españolas hechas anteriormente desde Santa Cruz de la Sierra. La palabra se encuentra usada para describir este edificio donde los mojos por Vasco de Solíz (1906 [1635]: 184) cuando comenta la jornada de Suárez de Figueroa de 1595-1596 que llegó entre ellos. Bomope es registrado en los diccionarios jesuitas con la siguiente definición: «ramada, bebedero antiguo de indios» (Marbán, 1699: 273). 
Amazonas (Chaumeil, 1985: 151-152; Karadimas, 1999: 394-395). Se puede leer bajo la pluma de un misionero que algunos de los indígenas de la región de Mojos fabricaban «sartas de los dientes y muelas de los hombres que matan» (Orellana, 1704: sp) pero el contexto del texto no permite adscribir la práctica a los arawak hablantes que nos interesan aquí. Parece en este caso que se refiere a los canisianas para quienes tenemos claras evidencias de la producción de tales trofeos (Beingolea, 2005 [ca. 1764]: 178)9. En cambio el uso de los dientes de jaguares entre los mojos es comprobado:

A modo de tahalí se ponen también los hombres muchas sartas de caracoles mezclados con dientes de tigre, lo mismo usan en la cintura, sino que la parte de la cintura que cae á las espaldas entretejen chaquiras grandes y cañutos de plata (Marbán et al., 1898 [1676]: 149).

Lamentablemente esta mención no permite confirmar ni negar que los dientes de jaguar eran sacados al momento de la preparación del trofeo ya que hubieran podido ser montados en sartas como una manera de reciclar los dientes de un trofeo antiguo ${ }^{10}$. El «hombre de la Loma Salvatierra» cuya tumba (fechada entre 600-700 d. C.) fue excavada a proximidad del territorio de los arawak ribereños históricos, tenía varios adornos (incluso de metal). Entre estos se encontró un collar reuniendo los cuatro colmillos de un jaguar (Prümers, 2007: 110-113). Como casi 1000 años separan a este hombre de la llegada de los jesuitas, sería sin embargo muy arriesgado sacar cualquier conclusión.

Sabemos finalmente que los cráneos-trofeos de jaguares y de humanos no recibían un nombre específico: se hacía referencia a ellos a partir del término significando «cabeza» (-chuti). Este nombre siendo un sustantivo inalienable, una construcción gramatical particular permitía saber que se trataba de una cabeza «desposeída» o «alienada», es decir separada de su cuerpo y propiedad de un tercero ${ }^{11}$. Notemos que si el cráneo era el principal trofeo que conservaban los mojos, no era el único. Exponían también en su casa colectiva la piel preparada, las patas (los tarsos y las garras) (Del Castillo, 1906 [ca. 1676]: 359). Esta colección no es anodina: significa que del cuerpo descuartizado se conservaban tanto las «armas» del animal (cráneo y dientes, patas y garras) como su «vestimenta» (piel). Hemos visto (ver más arriba) que flautas podían ser confeccionadas con los huesos largos de los humanos; no sería sorprendente que los mismos huesos del jaguar hayan podido tener un uso similar.

9 Los canisianas (de idioma aislado) eran los vecinos septentrionales de los mojos del Mamoré y sus enemigos encarnecidos. Fueron reducidos en la misión de San Pedro de Canichanas en 1697.

10 Por ejemplo los mundurukús quitaban los dientes de las cabezas momificadas en un ritual que marcaba la «muerte» del trofeo; luego hacían cinturones con ellas (Menget, 1996: 137).

11 Marbán (1699: 303) indica: «nu Chutì, cabeça y «ne Chutirà, las cabeças que tenian colgadas por señal de triunfo, ò por supersticion». Ese giro gramatical se conserva en mojeño ignaciano, idioma procedente del mojo descrito por Marbán y hablado en la misión de San Ignacio: «nuchuti 'mi cabeza' (parte de mi cuerpo); nuyehe chutire 'mi calavera (de otra persona o de un animal)» (Ott \& Burke de Ott, 1983: 22). 


\section{3. ¿DIOS-JAGUAR O ALMA DE VÍCTIMA FELINA?}

La descripción de la producción de los trofeos hecha hasta aquí brinda más que todo informaciones sobre la relación de los matadores y de su comunidad con la fiera matada: se adivina que, para los mojos, la sangre vertida en la matanza tenía la misma importancia que en otras partes de la Amazonía y que era necesario protegerse de ella. Se presiente que el lavado en el río, al mismo tiempo que la pintura negra, estaban ligados a un proceso de «descontaminación» y/o de protección de los mismos matadores, prealable a la necesaria reclusión que seguía. En cambio se percibe con dificultad las relaciones que podían existir con el cráneo y su contraparte personificada o «alma». Tales detalles no asequibles tan fácilmente hubieran podido pasar desapercibidos a los jesuitas, pero alcanzaron un papel de tal magnitud posteriormente a la reclusión que no pudieron pasarlos por alto. Crucialmente articuladas con el complejo chamánico mojo por un lado y distintas de la norma de los rituales poshomicidas conocidos de la Amazonía por otro, fueron incluso estas relaciones las que indujeron a los jesuitas a postular la dimensión «idólatra» de los trofeos.

Inmediatamente después del final de la reclusión de los «jaguaricidas», los mojos organizaban una sesión chamánica especial en la cual participaba toda la comunidad. Para ello, tanto los matadores como el chamán se hacían cortar la punta de los cabellos. Este corte no era específico a esta circunstancia pero marcaba el fin de cualquier «ayuno» preparativo a una sesión chamánica. Siempre nocturnas -y organizadas en cuanto fuera posible en las noches las más oscuras posibles, durante el novilunio-, estas sesiones consistían en invitar los espíritus en la casa colectiva «bebedero». Dos rasgos del régimen de comunicación con los espíritus en el transcurso de estas sesiones merecen ser resaltados. En primer lugar se trataba de acoger los espíritus como comensales para compartir con ellos una chicha ritual o «supersticiosa» (Marbán, 1701: 115) que recibían «físicamente» los espíritus de mano del chamán. La sesión era la ocasión de consumir una gran cantidad de chicha y terminaba en una «borrachera» colectiva. Fue incluso esta palabra que los jesuitas usaron por metonimia para referirse a la sesión chamánica misma12. En segundo lugar, durante estas sesiones nocturnas, los invitados espirituales permanecían siempre invisibles a los ojos de los presentes. En cambio, a falta de contacto visual, se los podía oír. Ignoramos los detalles del dispositivo material que permitía al chamán lograr tales resultados. Sabemos que movilizaban en este contexto una pieza de mobiliario en la cual era posible «entrar». Por analogía funcional algunos jesuitas la llamaron «púlpito»:

Entranse éstos en su púlpito y allí predican un atropellado de cosas en voz mediana, que ni el mismo que las dice, las entiende (Del Castillo, 1906 [ca. 1676]: 353).

12 Tal elección terminológica era aún más fácil de hacer puesto que ocurría en un lugar llamado «bebedero». 
Estas palabras eran cantos como lo interpreta con pertinencia Métraux (2013 [1943]: 246). Su aparente ausencia de sentido —incluso para quien canta - no significa que no tenían sentido para quienes eran llamados. Pero no es suficiente para saber si los chamanes mojos usaban un «idioma esotérico» comprensible para los espíritus. Por ejemplo los chamanes chimanes usan cantos que ni ellos ni el público y tampoco los espíritus entienden; sin embargo, cuando los escuchan, saben que son llamados (Daillant, 2003: 343-344).

Para propiciar estas invitaciones el chamán oficiante era un especialista particularmente renombrado Ilamado tiharauqui. No se trataba de un simple curandero, pero de un especialista de alto rango reconocido como capaz de ver a los espíritus y de interactuar con ellos tanto en privado como en público. Cuales fuesen las circunstancias que reclamaba la invitación de espíritus, los chamanes tiharauqui actuaban de la misma forma.

[El] demonio venia de noche y le pedia de beber [al chamán], y aunque no le veian, le oian todos. Concurrian juntos á la bebida y gastaban muchos dias en el cortejo á su dios, que, bebido un mate de chicha, los dejaba en su embriaguez (Eguiluz, 1884 [1696]: 54).

Ahora bien, en la sesión que seguía la muerte de un jaguar -la más solemne según un jesuita (Anónimo, 2005 [ca. 1754]: 107)— no cualquier tiharauqui podía oficiar: se requería un chamán que poseyera relaciones personales con un espíritu llamado por los jesuitas el «dios-jaguar» o «tigre-invisible». Volveremos sobre estos especialistas luego, pero veamos por el momento cómo actuaba el tiharauqui.

Celebraban el tigre muerto con grandes ceremonias: [...] hac[ían] chicha abundante para brindar á su dios y á todo el pueblo. Á aquél le hacía el brindis su particular hechicero, [...] y dicen que le aceptaba el demonio, de noche, en un rincón del bebedero, dando el mate por detrás, sin dejarse ver de nadie. [...] Entonces se publicaba cómo aquel dios era el que había muerto el tigre (Orellana, 1906 [1687]: 9).

La organización de las sesiones chamánicas descritas aquí, tanto bajo su forma genérica como en el caso que seguía la matanza de un jaguar, sigue un modus operandi que, si bien no parece muy difundido en otras regiones de Amazonía, es bien conocido localmente. Poniendo de lado algunos detalles sin mucha importancia a esta escala de comparación, es perfectamente comparable con el desarrollo de las sesiones chamánicas descritas por Isabelle Daillant donde los chimanes (2003: 342-356)13. Estas se realizaban en una casa ritual, de noche, en la oscuridad la más completa y también consistían en invitar a los espíritus para tomar chicha (a veces también una chicha especial). Para llamarlos el chamán manejaba principalmente un tambor e interpretaba cantos «incomprensibles» (como ya mencionado). Luego los espíritus se presentaban uno por uno, en persona. Recibían bebida pero quedaban invisibles para la congregación reunida

13 Estas sesiones corresponden también a las que algunos chamanes yurakarés realizaban en la región fronteriza con el territorio chimane hasta fines de los años 1980 (Hirtzel, 2010). 
y comunicaban con ella por el discurso. Se trataba, en fin, de un convite con huéspedes de marca.

La comparación de las sesiones chamánicas mojas con las de los chimanes esclarece retrospectivamente las primeras, pero deja sin embargo una dificultad: ¿cómo identificar este «dios/demonio» jaguar? y iqué pensar de la «proclamación» pública mediante la cual afirmaba que era él, el asesino del jaguar cuya calavera acaba de volverse un trofeo? Esta proclamación pareció al mismo jesuita que la describe como bastante incongruente: quedó asombrado y algo insatisfecho con la idea que el «dios-jaguar» pueda afirmar que era él mismo el matador «como si no bastara para que muriese la flecha del indio» (Orellana, 1906 [1687]: 9). El aspecto contra-intuitivo de la descripción no lo llevó a preguntar más detalles a sus interlocutores y prefirió pensar que «así enredaban otros disparates, de que eran ministros los hechiceros» (Orellana, 1906 [1687]: 9). Sería injusto tirarle la piedra a un sacerdote del siglo XVII por no interesarse de más cerca en las prácticas de un «hechicero». Pero la obscuridad del asunto parece sobre todo el resultado de una falta de comprensión de su parte. Sabiendo que esta invitación espiritual marcaba la muerte de un jaguar y que los mojos, al igual que todas las poblaciones amazónicas, se preocupaban del destino del «alma» de la víctima, se puede sospechar que el extraño invitado era menos un «dios-jaguar» matador que el alma del jaguar matado. Además, no era difícil equivocarse sobre la identidad de la entidad invitada perdiendo la información gramatical relativa a este participante. Hasta las formas castellanas no son fáciles de distinguir como se notará si oponemos «jaguar matado» a «jaguar matador». Restituir al invitado la identidad del alma del jaguar matado es conforme con el «sentido común» de tales sesiones, pero se armoniza además con otros elementos de su descripción.

En las sesiones chamánicas ordinarias, los espíritus que se presentan al tiharauqui son entidades normalmente «amigas» del chamán (se trataría incluso de parientes en el caso de los chimanes) que reclaman o piden bebida. En el caso de la sesión consagrada al jaguar muerto, su contraparte espiritual no muestra mucho afán para tomar. La descripción menciona solamente que «acepta» la bebida, como si «aceptar» fuera un gesto esperado pero no garantizado. Tratándose del alma de un jaguar muerto, como lo argumentamos aquí, se entendería inmediatamente su significación. El gesto de invitar chicha correspondería a una ofrenda de paz y recibirla a su aceptación. Otro elemento apunta hacia la misma dirección: según el mismo jesuita, por su contacto estrecho con el «dios-jaguar», el tiharauqui era capaz de desvelar el nombre propio del jaguar al matador. Se ve en qué medida tal observación encaja con la aparición pública, durante una sesión chamánica, del alma de la víctima. Recibir un espíritu, en tal circunstancia, supone que decline su identidad. Conocer la identidad de un espíritu de visita - conocer su nombreera esencial en las sesiones chamánicas tanto chimane como yurakaré y hay, por lo tanto, buenas razones para pensar que los mojos tenían las mismas expectativas. La obtención del nombre proprio de la víctima felina por el intermedio de la actuación de un chamán es un punto que merece que nos detengamos, puesto que es esencial para precisar los lazos entre el matador, el jaguar matado y el 
trofeo. Según la fuente que trata del tema, la revelación del nombre de la víctima tenía consecuencias sobre la identidad nominal del matador (hasta de un cazador que hubiera solamente herido un animal):

Á éstos [tiharauqui] acuden todos los que flechan ó matan tigres, para que les rrevele el nombre del flechado ó muerto; el cual cogen para sí, llamándose en adelante con aquel nombre, y por él son más conocidos que por el que les pusieron cuando niños sus padres (Orellana, 1906 [1687]: 8-9).

En el caso de la producción de un trofeo, el nombre del jaguar muerto correspondía al cráneo colgado en la casa colectiva, pero se volvía, al mismo tiempo, un nombre adicional que prevalecía luego para el matador (no se dice tampoco que venía a remplazarlo). Esta identificación onomástica entre el matador, su víctima y la calavera recuerda numerosas menciones etnográficas de tierras-bajas. En particular, muestra una indudable similitud con el proceso de adquisición de nuevos nombres por los hombres tupinambas que, cada vez que mataban un enemigo, se daban un nombre adicional, volviéndose detentores de una cadena de identidades onomásticas que iba creciendo, conforme a la cantidad de homicidios que habían perpetrado. La comparación es aún más pertinente si se toma en cuenta que, como sugieren las fuentes, los nuevos nombres, públicamente desvelados por los matadores en una fiesta de bebida, eran considerados como los nombres de sus propias víctimas (Viveiros de Castro, 1992: 152). La similitud general entre ambos casos no significa sin embargo que se puedan analizar de la misma manera.

Es importante notar, en el caso de los mojos que, por un lado, un humano podía tener el mismo nombre que un jaguar vivo (que fue solo herido) y por otro lado, que cualquier transmisión de nombre se hacía mediante un tercero: era el chamán el garante de esta realización, no el «jaguaricida». A la diferencia de los tupinambas la adquisición del nuevo nombre no era interna, simbiótica y «fusional» sino externa, homonímica y «referencial». Donde los tupinambas la identificación onomástica puede analizarse como el índice del «deseo» individual del matador de nombrarse como su enemigo (para seguir el análisis de Viveiros de Castro); donde los mojos, en cambio, refleja el deseo social implícito (por la intromisión de un tercero, el chamán) que un nombre de enemigo se vuelva un nombre de pariente. Volveremos luego sobre el significado de este proceso del cual una parte se nos escapa mientras los usos sociales del trofeo (y por lo tanto del alma que le queda vinculada) no han sido examinados. En todo caso es relevante mencionar aquí que la homonimia era posible entre los mojos: la forma ni-ha «mi nombre» era una expresión vocativa que ego podía usar para dirigirse a un alter homónimo (Marbán, 1699: 304)14. Por otra parte, esta demostración es confirmada por un hecho singular que se debe examinar ahora. Si bien, entre los

14 El diccionario misionero indica: «ni Hà, dizen al que tiene su mismo nombre, llamandolo, ò hablando con èl.; ni Ha, mi nombre; ni Harè, mi nombre, ò el de mi mesmo nombre» (Marbán, 1699: 304). Tanto en trinitario como en ignaciano contemporáneo se han mantenido formas para notar la homonimia de dos nombres proprios o una relación de tocayo: trinitario «-cheja: tocayo, ej. persona con el mismo nombre o apellido» (Gill, 1993 [1970]: 9); «tíjarureca (modismo) el tocayasco, un [sic] costumbre para dar nombres (apodos) ignacianos» (Ott \& Burke de Ott, 1983: 399). 
mojos, el matador de jaguar no se volvía jaguar, existía donde ellos alguien que, mucho más que el matador, participaba de una identidad felina: el tiharauqui que intercedía por él y para clausurar la instalación de los trofeos.

\section{INTERCAMBIOS DE MIRADAS Y UN POCO MÁS}

El tiharauqui de tipo chamán-jaguar, capaz, como lo proponemos aquí, de invitar al alma de un jaguar víctima, alcanzaba su estatus de intercesor por haber sido él mismo víctima del asalto de uno de estos felinos. Como prueba del abrazo al filo de la muerte que había tenido con la fiera debía ostentar las cicatrices de sus colmillos o de sus garras. Este tiharauqui era de esta manera tanto un sobreviviente como un «elegido» que el jaguar no había matado o comido, capaz desde luego de verlo, como ningún otro, es decir como persona. Se trascendía así el encuentro predador cara a cara y la mezcla de cuerpos del combate en una intimidad y una familiaridad que no podía lograrse de otra forma. Tenemos dos descripciones de este evento hechas por el mismo misionero con algunos años de intervalo:

[E]l que haviendo caído en ellos se libraba de sus garras, le miraban como especialmente excogido y amparado de su dios, siendo los dientes del tigre como un sacramental carácter con que le señalaba y segregaba de los demás para su ministro (Orellana, 1906 [1687]: 8).

Y no todos podían ascender à este honor, sino solo aquellos que aviendo sido heridos, y maltratados de la fiereça de vn Tigre, tuvieron la dicha, de escapar con vida de sus garras, venerando la gente como à hombre de superior virtud, al que à su parecer fue respetado, y favorecido de otro Tigre invisible, y contrario al que le acometió (Orellana, 1704: s. p.)

No se debe olvidar a manera de advertencia que el combate iniciático presentado aquí toma una forma idealizada. Por lo tanto, se debe descartar como no pertinentes las situaciones reales donde un humano herido por un jaguar hubiera logrado matarlo. La coherencia del caso requería un hombre herido y al mismo tiempo un jaguar vivo. Como tal situación no era muy común existían maneras de incrementar su frecuencia. Dos ejemplos que no provienen directamente de los mojos darán una idea de los medios usados para este fin. Entre los baures el chamán, llamado por ellos motire, podía llegar herido al pueblo como si hubiera peleado con el jaguar:

Para hacerse de mayor prestigio entre los suyos y ganar y obtener bienes, a menudo el motire se lacera un poco con sus uñas, se tira de los cabellos, afirmando que ello es obra del tigre (Eder, 1985 [ca. 1772]: 115-116).

Aunque sin referencia explícita al jaguar recogí, entre los yurakarés del Alto Sécure, el testimonio de una mujer que enunciaba algo similar: el hijo de un famoso chamán de la región había querido seguir los pasos de su padre y emprendido una «iniciación»: una vez, después de haber desaparecido un largo tiempo en el monte, llegó, él también, todo arañado y herido. Deducía la mujer que era por haber peleado con sus «amigos» (espíritus). 
Para entender mejor los asaltos del jaguar como manera potencial de volverse tiharauqui, es importante examinar los otros procedimientos que se ofrecían para acceder a tal estatus. Si no eran todos del mismo orden, requerían, en cambio, siempre una «visión», correspondiendo a una captación admirable y sumamente aterradora de su propia mirada por la del espíritu (cf. Taylor 1993; Viveiros de Castro, 2012).

[Los tiharauqui eran] escogidos para este misterio por aparición de alguno de sus dioses, que se hacía con demostraciones exteriores de accidentes gravísimos, que repentinamente los privaban de sus sentidos y los ponían á peligro de muerte (Orellana, 1906 [1687]: 9).

Estos «accidentes graves» no necesariamente tenían lugar lejos de la comunidad y concernían tanto hombres como mujeres: una repentina estupefacción seguida de crisis de lágrimas o una súbita e inexplicable pérdida de conocimiento podían bastar. Estos bruscos cambios de estados somáticos, corroborados por los parientes de las «víctimas», eran vividos y socializados inmediatamente como pruebas indirectas pero fehacientes de una «visión de espíritu» privada. Los jesuitas tuvieron la oportunidad de documentar dos casos de este tipo involucrando a mujeres. Veamos la descripción del caso observado con más detalle:

Una muchacha [...] fue hacia el río y apareciósele en forma de mujer el diablo, llamóla por su nombre y no sé lo demás que pasó. De lo que soy testigo, es que estaba su padre con nosotros y vino la madre muy llorosa, díjole en su lengua, que no la entendemos, lo que pasaba; él se levantó asustado, juzgamos que á la hija le había dado algún accidente mortal: fue allá el padre Pedro [Marbán] y yo le seguí y hallamos á la muchacha cerrada la puerta dentro de su casa; sentada en el suelo, con un llanto y voces raras cantando y llamando á su dios, cerrados los ojos y pasando continuamente la mano por ellos, sin cesar un punto de cantar llorando con tales tonos, fatiga y tezón, que yo hice entero concepto que estaba poseida de algún mal espíritu. [...] Vino el padre [Cipriano Baraze] y todos tres estuvimos, hasta nos cansamos de oirla y ella no se cansó de tanto afán y fatiga en su llanto, voces y refregarse los ojos, diciendo en su idioma: ven, ven dios mío; y esto, con una ancia indecible. El padre se alegró y dijo, dejen a mí hija que ha de ser Tiaranqui [sic], [...] Salimos, quedó allí el padre, ella había arrojado los yupesires ${ }^{15}$ como protestando que no era ya del mundo: el padre, cuando nos salimos, le acabó de desnudar de chaquiras y de todo arreo, cerró otra vez la puerta, y ella por gran rato prosiguió con su raro llanto. En confirmación de esto, empezó el ayuno; [...] Prosiguió el ayuno, hasta que hicieron la borrachera; ella se engalanó a su modo y quedó en opinión de hechicera (Del Castillo, 1906 [ca. 1676]: 356).

El proceso electivo descrito en este caso empieza con una interpelación repentina: un espíritu llama a la «víctima» por su propio nombre. Esta llamada genera un

15 «Yupesirirè, nuyupesirì, el dige redondo de las narizes» (Marbán, 1699: 377). 
contacto visual privado cegador. La muchacha cierra los ojos y, luego, no para de frotárselos mientras se corta la comunicación ordinaria con ella: por un lado pide al espíritu que venga, por otro, comenta su estado como un estado de «muerte». Esta extraordinaria descripción evidencia una configuración que se traspone sin dificultad a un asalto de jaguar. El felino agresor, quien sorprende la víctima, se presenta como la versión «material» y agonística del choque espiritual sentido, en otros casos a través de una visión de espíritu privada. El desarrollo de la interacción sigue en ambos casos, la misma progresión: un jaguar o un espíritu invisible, ven primero a su víctima, le aparecen de manera fulminante en el asalto o llamándola, un intercambio de miradas se realiza y esta aparición provoca una experiencia confinando con la muerte: quien sobrevive será desde luego capaz de pasar y acceder en permanencia «al otro lado» es decir capaz de interactuar de manera personal con los espíritus.

Se notará, por lo tanto, que la figura del «dios-jaguar» o del «jaguar invisible» mencionada arriba, no es más que una sombra que puede fácilmente ser borrada de la descripción. Aparece bajo la pluma del misionero por las mismas dificultades de interpretación que las evocadas cuando se analizó la sesión chamánica. No era concebible para este jesuita que un animal vivo pueda ser al mismo tiempo un espíritu, o para decirlo usando su vocabulario, que el jaguar «visible» sea la misma entidad que el jaguar «invisible» futuro amigo del chamán. No obstante, otros de sus correligionarios pudieron entender la situación de manera distinta. Bastaba identificar al agente inicial de estos encuentros como el diablo:

Unas veces se les aparecía [el demonio] como rayo que caía del cielo; otras, en forma de un gigante; otras, con figura de caimán o tigre; y, siempre, causando terror y espanto en los que le oían y veían (Anónimo, 2005) [1754]: 109).

El papel fundamental de esta visión inicial —la captación por el espíritu—era una condición necesaria para desarrollar el oficio de tiharauqui. Pero después los candidatos tenían que cumplir con otros requisitos: entrar en una larga fase ascética con «ayunos» y recibir una formación explicita de un colega. Podían empezar a llamar los espíritus solamente después de un ritual de agregación que consistía en la introducción en el ojo del zumo de una raíz (indeterminada):

Merecen el sacerdocio y quedan como consagrados de mano del Sacerdote mayor (que es el más célebre hechicero) [una vez] que [este] les unge los ojos con el zumo de una raíz de un bejuco picante y mordaz, que les aclare, a costa de mucho escozor y llanto, la vista para ver y conocer las cosas que su Dios les revela (Marbán, 2005 [1700]: 55-56).

Podemos constatar que este ritual repetía, a través de un proceso llamado neceracho ${ }^{16}$, el deslumbramiento inicial provocado por la aparición del espíritu. Perder la vista ordinaria permitía conseguir otra vista. Este proceso era esencial

16 «ne Ceracho, vntar los ojos à otro supersticiosamente para hazerlo curandero» (Marbán, 1699: 288). La forma verbal deriva de la raíz cera «lagrima». 
para los mojos. El propio nombre tiharauqui glosado a veces como «él de ojos claros» (Altamirano, 1979 [1712]: 55) tenía sin embargo menos que ver con la «Clarividencia» que con una calidad de mirada: «Suena tiaranqui [sic] el que tiene larga vista, y mas propiamente, el que tiene luz en los ojos.» (Del Castillo, 1906 [ca. 1676]: 357). Los datos lingüísticos jesuitas confirman que la palabra puede traducirse como «él de los ojos luminosos, resplandecientes»17.

\section{PREDADORES CONVERTIDOS}

La intervención del tiharauqui, para comunicar los nombres de las víctimas jaguares y, como lo sostenemos para llamar a la víctima misma, implicaba el mantenimiento y la prórroga posmortem de la individualidad de esta. No buscaban los mojos deshacerse de su «alma», y tampoco buscaban, como los jívaros, transformar la cara del enemigo o, mejor dicho, su «perfil» (así llaman la cabeza reducida), en la promesa abstracta de una vida a nacer (Taylor, 1994). El arte «husserliano» de la reducción era sustituido por un arte del reciclaje y de la restauración para una conservación futura. Esto se nota por el hecho de privilegiar la calavera (una materia ósea durable), pero también por el hecho de añadir a esta cabellos de sustitución y, en el caso de los cráneos humanos, ojos postizos (de un color rojo que no es tal vez indiferente al tema de la incandescencia ocular del tiharauqui). Esta introducción de «nuevos ojos» en las órbitas de la calavera aseguraba la reconversión de los cráneos y consistía en una operación absolutamente distinta a la de coser los párpados como lo hacen los jívaros para producir las cabezas reducidas. Hechos para durar, los trofeos eran por lo tanto concebidos para volverse actores de pleno derecho entre sus «dueños», pero ide qué manera? Un jesuita nos da elementos interesantes para entender lo que pasaba con las calaveras de enemigos humanos. Según él, «el demonio» jugaba un importante papel en el desarrollo de sus guerras:

Tenían aviso previo de que alguna nación se armaba contra ellos, y esto lo tenían muchas veces por el Demonio, que hablaba con el hechicero, [...]. El promotor de estas guerras era el Demonio, que los instigaba por boca de los hechiceros, prometiéndoles siempre victorias y felicidades, siendo así que, después de sus promesas, volvían vencidos muchas veces y los vencedores, con poca ganancia y mucha pérdida de gente; pero con todas estas experiencias que el Demonio los engañaba, que tantas veces los cogían en mentiras, ciegamente los consultaban y creían como a infalible oráculo (Anónimo, 2005 [1754]: 109).

¿A quién más que a los cráneos-trofeos humanos de enemigos el «demonio de la guerra» evocado aquí podía hacer referencia? ya que hemos mencionado (ver introducción) que eran consagrados al «Dios de las guerras». La credibilidad de

17 La palabra se compone de dos raíces principales hara («luz») e uqui (ojo). Marbán (1699: 306) define «ti Haray» por «resplandecer el Sol, ser de día, aclarar el tiempo». Ver también «nu Hararaaconè, tener el cuerpo encendido, resplandeciente» o «Harairiqui, Estrella» (Marbán 1699: 306). 
esta interpretación queda aún mejor establecida, si tomamos en cuenta que movilizar trofeos con este fin no es una invención idiosincrásica de los mojos: las poblaciones del Chaco hacían lo mismo con los scalps de sus enemigos. Entre los nivacles, el dueño de estos trofeos (caanvacle) mantenía lazos personalizados y estrechos con las almas de los enemigos matados, unidas a las cabelleras que cuidaba. Una vez plenamente controladas, se volvían auxiliares de guerra y actuaban por él «como 'espías' o 'informantes'», transmitiéndole datos «sobre las amenazas eventuales en contra de su gente y sobre todo lo que concierne las fuerzas enemigas»; también «le asistían y le sostenían durante las operaciones dictándole las arengas que debía pronunciar» (Sterpin, 1993: 49, trad. propia).

La función cumplida por los cráneos de jaguar no queda documentada directamente, pero se puede sospechar que, por lo menos, podían servir a protegerse de los asaltos de otras fieras. Se entiende así mejor porque, después de la llegada de los misioneros y la destrucción de estas reliquias, la cruz haya podido tomar el relevo: como un trofeo, alejaba el mal; además como metonimia de la pasión del Cristo, reverberaba tal vez las mordidas por el jaguar de los tiharauqui.

Sin llegar tan lejos, otras prácticas relativas a los cráneos animales ayudan a precisar esta «fuerza repulsiva». A los mojos les gustaba conservar no solamente las calaveras de los enemigos y predadores, sino también las de las presas que consumían:

Colgaban alre(de)dor de sus casas las cabezas de los animales y pájaros que flechaban y las cáscaras de huevos de avestruces y otras aves: (unas, por superstición y juzgando que aquellas calaveras daban fortuna para aquella casa; y otras, por hacer alarde y jactarse de ser grandes cazadores) (Anónimo, 2005 [1754]: 96).

Hoy en día todavía, a proximidad de sus casas, algunos lejanos descendientes de los mojos cuelgan y exponen los huesos de las presas que han matado y consumido, para comunicar con los animales que cazan a fin de mantenerlos en su vecindad:

Cuelgan los cráneos de animales cazados (tapir, jochi, tigrecillo nocturno, tatú, taitetú) de los árboles en el entorno de algunas viviendas. Ello se hace «para que el espíritu de los animales no se aleje mucho de sus viviendas» (Querejazu Lewis, 2008: 315).

Si los cráneos de presas son expuestos para facilitar la caza y funcionan como imán, es entonces perfectamente comprensible que cráneos de predadores —como el jaguar- pudiesen haber tenido la virtud inversa, pues si se quiere animales para comer, no se quiere que un jaguar venga a comer, sea bajo su forma de fiera, sea bajo una forma espiritual18.

18 Los urarinas del norte del Perú muestran otro ejemplo de preocupaciones similares. Los cazadores cuelgan sistemáticamente las mandíbulas de sus presas en sus casas. Algunos pueden decir que es para embellecerlas, otros para mostrar que son valientes cazadores. Pero existe todavía otra explicación: «Las colgamos porque se dice que si no se hace, un espíritu del monte entra en la casa 
La conservación de la calavera del jaguar con este objetivo es además atestado en la región. Los yurakarés la ponen todavía en práctica, aunque nunca se haya mencionado en su etnografía, tanto antigua como contemporánea, un complejo de trofeos del mismo orden que en el caso de los mojos. A principios de los años 2000, estuve en el alto río Sécure donde un hombre que guardaba discretamente en su casa, sobre un estante, dos cráneos de jaguares que había matado (fig. 1). Puesto en este lugar para evitar que los niños los hurguen, habían sido objeto de un tratamiento específico para neutralizar su potencia predadora. Se encontraban enrollados con un alambre que impedía que abran la boca, un dispositivo que mi huésped comparó con un bozal. Me explicó además que sus «dueños» (término equivalente a «alma») seguían ahí y que ahora servían para alejar de su casa, aislada del pueblo, los jaguares que hubieran podido atacar a sus perros o a los chanchos que criaba. Los «dueños» se comunicaban con los jaguares de carne y hueso solicitando que «no molesten» y que vayan a cazar por otras partes. Añadiré que el hijo de este hombre me obsequió por amistad una calavera de jaguar que conservaba (sin alambre) afirmándome que con ella iba a poder «andar tranquilo». Precisó que iba a ser el caso por lo menos mientras no se partan los colmillos por la mitad lo que significaría que el dueño se hubiera ido. «Tienes que cuidarlo» dijo con una sonrisa llena de picardía...

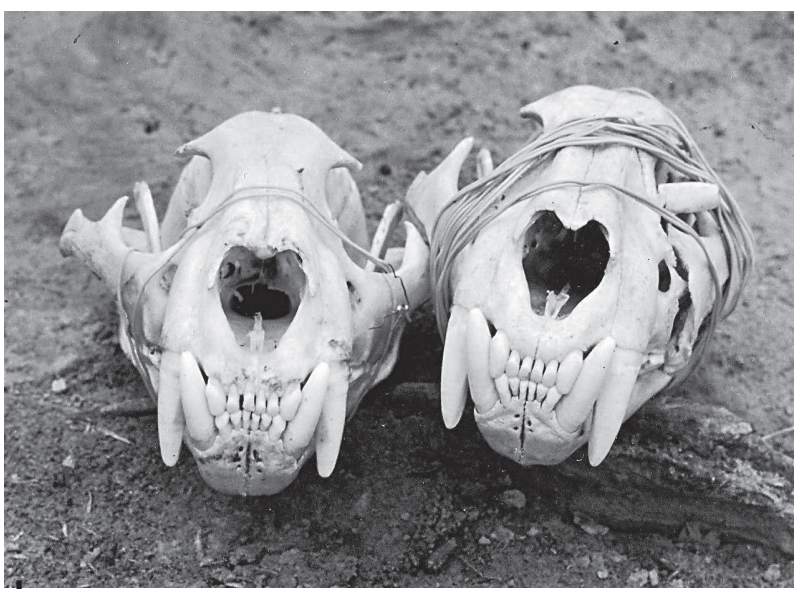

Figura 1 - Dos cráneos-trofeos de jaguares conservados por un hombre yurakaré (Alto-Sécure)

(C) Vincent Hirtzel, 2000
Los cráneos trofeos conservados por los mojos eran activos sobre el registro de la guerra y de la protección y hechos para durar; no eran tan efímeros como otras cabezas trofeos tales las de los jívaros o de los mundurukús. Es importante recalcar el hecho de que estamos, entre los mojos, frente a trofeos de huesos. Este detalle no es trivial, pues pueden cumplir así una función social de largo plazo como todos los vestigios conservados de esta materia (Chaumeil, 1997). Se trata de restos de humanos y de animales que, al ser elaborados ritualmente, adquieren por así decirlo, una nueva vida: su producción en cuanto trofeo se sustituye al proceso de duelo que hubieran recibido por sus parientes. Las almas de enemigos de humanos o de jaguares podían volverse así «aliadas» con sus matadores: refuerzos contra su exparientes o guardias haciendo obra de disuasión con sus excongéneres, se convertían a la causa de sus dueños. Este cambio de campo puede ser analizado,

y en vez de agarrar la mandíbula, agarrará la tuya, la de tus hijos o de tu mujer» (Fabiano, 2015: 117, trad. propia) En este caso, los huesos que no son personalizados, funcionan como medios defensivos que canalizan fuerzas agresivas. 
con Carlos Fausto (2012 [2001]), como un proceso de familiarización pero, en este caso, la familiarización no es solamente un proceso predador invertido (o neutralizado). Corresponde a una estrategia de guerra ofensiva o defensiva que tiene por fin tomar la delantera sobre sus enemigos o sus predadores. Adquirir trofeos es fundamentalmente un proceso de «conversión»: al mismo tiempo que son «integrados» los huesos guardan de su antigua identidad lo suficiente para poder comunicar con sus excongéneres, no sin dejar de servir a su dueño, quien no es más que su asesino.

Revisar una etnografía del siglo XVII realizada por misioneros deseosos de aportar las luces del evangelio a unos bárbaros mantenidos en las tinieblas de la ignorancia no es una tarea fácil: requiere trazarse un camino entre los prejuicios y la falta de información, aclarando indicios por comparación —ora por contraste, ora por semejanza - para atribuirle una mejor inteligibilidad. Tal ejercicio requiere cautela a la vez que supone escoger orientaciones interpretativas. Pero a pesar de las vicisitudes del método y de sus inevitables claroscuros, emerge una coherencia global bastante sólida que demuestra que el caso mojo es muy pertinente y útil para tener una visión más global de la problemática de los trofeos en Suramérica. La asociación excepcional a este nivel de cráneos humanos y jaguares se desvela como un proceso dirigido hacia la producción de nuevos «medios de guerra» dentro de una economía de eliminación de enemigos y predadores que buscaba también una plusvalía: se trataba de convertir las victimas conservando los restos duraderos de sus huesos, en aliados ofensivos o defensivos. Pero sobresale el papel clave de los jaguares en este proceso, porque aportaban a los mojos algo más: en sus imprevisibles asaltos podían generar una interacción que se ubicaba en la cadena de todas las situaciones de estupefacción espiritual: los jaguares como generadores de chamanes, se presentan como una «tribu-especie» (Descola, 2005) singular. Entre los mojos el jaguar (y tal vez en menor grado, el caimán) podían volverse la transposición material de espíritus. ¿Un especie de dios encarnado?

Adoraban en cada pueblo muchos [dioses], unos particulares de ellos, otros comunes á todos, unos casados, otros solteros, cada uno con diferente empleo y ministerio; cuál presidente del agua y de sus peces, cuál de las nubes y rayos, otros de los sembrados, otros de la guerra y otros de los tigres. Y éstos eran los que tenían exterior [...] (Orellana, 1906 [1687]: 8).

El jaguar concluye una lista de seres, espíritus o «dioses», con atributos antropomórficos, pero sin contraparte corporal «ordinaria»: él, es único en tener un cuerpo visible públicamente, y no solamente de manera privada por el chamán. En este sentido el «exterior» jaguar, la «forma» jaguar, era el único cuerpo compatible con seres espirituales de los tipos aquí mencionados. Con este comentario no queremos decir que, entre los mojos, cualquier de los espíritus (o dioses) enumerados previamente podían manifestarse como jaguares, es decir tenían en el jaguar la posibilidad de encarnarse o mostrarse públicamente. Tal vez 
era el caso, pero no hay datos que permiten sostenerlo. En cambio muestra que el jaguar es, dentro de todos los animales, el único (o casi, si añadimos el caimán) apto a actualizar un espíritu, y por lo tanto a participar como otros espíritus a sesiones chamánicas (donde todos llegan para hablar pero sin dejar de ser invisibles). Esta situación muestra finalmente que, cuando los jesuitas afirmaron que el jaguar era la «única idolatría exterior», propusieron una formulación que no carecía totalmente de pertinencia.

El chamanismo chimane, del cual hemos ya señalado la proximidad con el chamanismo mojo antiguo, nos aporta una confirmación de que, en todo caso, no nos engaña la etnografía jesuita. Descubrimos con este grupo una manera bien particular de posicionar los jaguares, similar a la de los mojos. Entre ellos los espíritus que vienen de visita en las sesiones chamánicas (audibles pero invisibles) son de varios tipos: la categoría la más común se conoce como la «gente de dentro» (Daillant, 1998; 2003). Nada en este nombre recuerda un vínculo cualquiera con los jaguares, y aun así:

Fuera de las ocasiones rituales donde el chamán los invita y donde aparecen a todos bajo su forma humana, el profano que los encuentra en el monte ve en ellos un jaguar. Solo el chamán reconoce su verdadera naturaleza más allá de esta apariencia y puede incluso conversar con ellos (Daillant, 2003: 310; trad. propia).

Para los chimanes, todos «los de dentro» son «jaguares» en cierta situación, lo son también los «dueños de los animales». Pero la proposición inversa, en su caso, no es verdad. No todos los jaguares son «espíritus». Existen jaguares «normales», pero estos les interesan mucho menos. En todo caso no son ellos que vienen a visitarlos bajo una forma antropomorfa durante una sesión chamánica. Sin duda no es exactamente lo mismo pretender que cualquier jaguar es un espíritu potencial, como parece haber sido el caso donde los mojos, o pretender que cualquier espíritu es capaz de mostrarse como jaguar, como lo afirman los chimanes. Pero en ambos casos, los espíritus jaguaromórficos han podido ser anexados a su propio colectivo gracias al papel de los los chamanes: «gente como nosotros, pero...» para retomar la fórmula de Daillant (1998). En ambos casos también los espíritus y los jaguares se encuentran localizados en el inicio de una curva ontológica que tomando altura podría de manera sugestiva terminar en los Apu señores de los cerros en quechua o de los Mallku en aymara. Estos señores de los cerros ya no conforman una «tribu-especie»: son personas, espíritus, entidades tutelares, divinidades, como se quiere llamarlos. No por eso dejan de ser visibles como animales: no como el predador del monte, sino como el cóndor carroñero de las cimas cuyo nombre, no es otro, en aymara que mallku.

\section{Agradecimientos}

Agradezco a Philippe Erikson y a Jean-Pierre Chaumeil por sus comentarios de una versión previa de este trabajo. 
Los espíritus-jaguares: cráneos-trofeos y chamanismo entre los mojos (siglo XVII)

\section{Referencias citadas}

ALTAMIRANO, D. F. de, 1979 [1712] - Historia de la misión de los Mojos, 223 pp.; La Paz: Instituto Boliviano de Cultura (Biblioteca «José Agustín Palacios», 3). Edición de M. V. Ballivián.

ANÓNIMO, 2005 [1754] - Descripción de los mojos que están a cargo de la Compañía de Jesús en la provincia del Perú. In: Mojos, seis relaciones jesuíticas: geografía etnografía - evangelización, 1670-1763 (J. M. Barnadas \& M. Plaza eds.): 77-128; Cochabamba: Historia Boliviana.

BEINGOLEA, J. de, 2005 [ca 1764] - Noticia de las Misiones de Mojos. In: Mojos, seis relaciones jesuíticas: geografía - etnografía - evangelización, 1670-1763 (J. M. Barnadas \& M. Plaza eds.): 161-195; Cochabamba: Historia Boliviana.

BLOCK, D., 1997 [1994] - La cultura reduccional de los Ilanos de Mojos. Tradición autóctona, empresa jesuítica \& política civil, 1660-1880, 261 pp.; Sucre: Historia Boliviana. Traducción del inglés por J. M. Barnadas.

CHAUMEIL, J.-P., 1985 - Échange d'énergie : guerre, identité et reproduction sociale chez les Yagua de l'Amazonie péruvienne. Journal de la société des américanistes, 71 (1): 143-157.

CHAUMEIL, J.-P., 1997 - Les os, les flûtes, les morts. Mémoire et traitement funéraire en Amazonie. Journal de la société des américanistes, 83 (1): 83-110.

CORTÉS RODRÍGUEZ, J., 2005 - Caciques y hechiceros: huellas en la historia de Mojos, 113 pp.; La Paz: Plural Editores, Universidad de la Cordillera.

DAILLANT, I., 1998 - Ils sont comme nous, mais... Relations de parenté et de genre entre Chimane et «gens de dedans». Anthropologie et Sociétés, 22 (2):75-97.

DAILLANT, I., 2003 - Sens dessus dessous. Organisation sociale et politique des Chimane d'Amazonie bolivienne, 516 pp.; Nanterre: Société d'ethnologie (Recherches américaines, 6).

DEL CASTILLO, J., 1906 [ca. 1676] - Relación de la provincia de Mojos. In: Documentos para la historia geográfica de la República de Bolivia. Serie primera. Época colonial, vol. 1, Las Provincias de Mojos y Chiquitos (M. V. Ballivián, ed.): 294-395; La Paz: Imprenta de «El Comercio».

DENEVAN, W. M., 1980 [1966] - La geografía cultural aborigen de los Ilanos de Mojos, 272 pp.; La Paz: Librería Editorial «Juventud». Traducción del inglés por J. M. Barnadas.

DESCOLA, P., 2005 - Par-delà nature et culture, 623 pp.; París: Gallimard (Bibliothèque des sciences humaines).

DJUP, A., 2007 - Personhood and human-spirit relations among the Yuracaré of the Bolivian Amazon, 237 pp.; Gotemburgo: Göteborg University (Gothenburg studies in social anthropology, 19).

EDER, F. J., 1985 [ca. 1772] - Breve descripción de las reducciones de mojos, civ + 424 pp.; Cochabamba: Historia boliviana. Edición y traducción del latín por J. M. Barnadas.

EGUILUZ, D. de, 1884 [1696] - Relación de la misión apostólica de los Mojos en esta provincia del Perú [...]. In: Historia de la misión de Mojos en la República de Bolivia (E. Torres Saldamando, ed.): 1-64; Lima: Imprenta del Universo, de C. Prince.

FABIANO, E., 2015 - «Le corps mange, tout comme ma pensée soigne ». Construction des corps et techniques de contamination dans la pratique chamanique urarina, 406 pp.; París: École des hautes études en sciences sociales. Tesis de doctorado. 
FAUSTO, C., 2012 [2001] - Warfare and shamanism in Amazonía, xv + 347 pp; Cambridge, Nueva York: Cambridge University Press (Cambridge Latin American Studies, 96). Traducción del portugués por D. Rodgers.

GILL, W., 1993 [1970] - Diccionario trinitario-castellano y castellano-trinitario; s.l.: Misión Nuevas Tribus.

HIRTZEL, V., 2010 - Le maître à deux têtes : une ethnographie du rapport à soi yuracaré (Amazonie bolivienne), 742 pp.; París: École des hautes études en sciences sociales. Tesis de doctorado.

HIRTZEL, V. \& DAILLANT, I., 2012 - Los arawak del Mamoré y su politie al amanecer de las misiones jesuitas; Viena: ponencia presentada a Arawakan linguistic and cultural identities (Symposium 654), 54 ${ }^{\text {th }}$ International Congress of Americanists (ICA).

KARADIMAS, D., 1999 - L'impossible quête d'un kalos thanatos chez les Miraña de I'Amazonie colombienne. Journal de la société des américanistes, 85 (1): 387-398.

KARSTEN, R., 2000 [1935] - La vida y la cultura de los Shuar, 404 pp.; Quito: Abya-Yala. Traducción del inglés por M. C. Montano, G. Iglesias y H. Dueñas.

LEHM ARDAYA, Z., 1998 - Cabildos, hechiceros, sobadores y profetas: una aproximación al tema del poder entre los mojeños. In: XII Reunión anual de etnología, Anales de la Reunión Anual de Etnología: 145-160; La Paz: Museo Nacional de Etnografía y Folklore (MUSEF).

LEHM ARDAYA, Z., 2015 [1999] - El movimiento de búsqueda de la Loma Santa. In: Antología del pensamiento crítico boliviano contemporáneo (S. Rivera Cusicanqui \& V. Aillón, eds.): 317-362; Buenos Aires: Consejo Latinoamericano de Ciencias Sociales (CLACSO) (Antologías del pensamiento social latinoamericano y caribeño).

LOMBARDO, U. \& PRÜMERS, H., 2010 - Pre-Columbian human occupation patterns in the eastern plains of the Llanos de Moxos, Bolivian Amazonía. Journal of Archaeological Science, 37 (8): 1875-1885.

MARBÁN, P., 1699 - Arte, y vocabulario de la lengua morocosi. Compvesto por vn Padre de la Compañía de Jesvs, missionero de las provincias de los Moxos, 379 pp.; Madrid: [s.n.].

MARBÁN, P., 1701 - Arte de la lengva moxa con su vocabulario, y cathecismo, [16], 664, 142, [22], 163-202, [2] pp.; [Lima]: Imprenta Real de Joseph Contreras.

MARBÁN, P., 2005 [1700] - Breve noticia de las Misiones de infieles, que tiene la Compañía de Jesús de esta Provincia del Perú en las Provincias de los Mojos. In: Mojos, seis relaciones jesuíticas: geografía-etnografía-evangelización, 1670-1763 (J. M. Barnadas \& M. Plaza eds.): 53-66; Cochabamba: Historia Boliviana.

MARBÁN P., BARAZE, C. \& DEL CASTILLO, J., 1898 [1676] - Carta de los Padres que residen en la Misión de los Mojos para el Padre Hernando Cavero de la Compañía de Jesús, Provincial de esta Provincia del Perú, en que se le da noticia de lo que han visto, oído y experimentado en el tiempo que há que están en ella. Boletín de la sociedad geográfica de La Paz, I (1-2): 120-161.

MENGET, P., 1996 - De l'usage des trophées en Amérique du Sud : esquisse d'une comparaison entre les pratiques nivacle (Paraguay) et mundurucu (Brésil). Systèmes de pensée en Afrique noire, 14 (Destin de Meurtrier): 127-144.

MÉTRAUX, A., 1942 - The native tribes of Eastern Bolivia and Western Matto Grosso, ix, 182 pp.; Washington: Government printing office (Bulletin; Smithsonian institution, Bureau of American ethnology, 134).

MÉTRAUX, A., 2013 [1943] - Organisation sociale et religion des Mojos et des Manasí. In: Écrits d'Amazonie. Cosmologies, rituels, guerre et chamanisme (M. Brohan, J.-P. Goulard, P. Menget \& N. Pétesch, eds.): 233-267; París: CNRS Éditions (Bibliothèque de l'anthropologie). 
ORBIGNY, A. d', 1844 - Voyage dans l'Amérique méridionale (Le Brésil, la République orientale de l'Uruguay, la République argentine, la Patagonie, la République du Chili, la République de Bolivia, la République du Pérou), exécuté pendant les années 1826, 1827, 1828, 1829, 1830, 1831, 1832 et 1833, Vol. 3, 1 ${ }^{\text {ère }}$ partie, Partie historique, 474 pp.; París, Estrasburgo: P. Bertrand, Veuve Levrault.

ORELLANA, A. de, 1906 [1687] - Carta del Padre Antonio de Orellana, sobre el origen de las misiones de Mojos. 18 Octubre 1687. In: Juicio de límites entre el Perú y Bolivia. Prueba peruana presentada al Gobierno de la República Argentina, t. X, Mojos II (V. M. Maurtua, ed.): 1-24; Barcelona: Imprenta de los Hijos de G. M. Hernández.

ORELLANA, A. de, 1704 - Relacion summaria de la vida, y dichosa muerte del U.P. Cypriano Baraze de la Compañia de lesus, muerto á manos de barbaros en la Mission de los Moxos de la Provincia del Perù, s.p.; Lima: En la Imprenta Real de loseph de Contreras.

OTT, W. \& BURKE DE OTT, R., 1983 - Diccionario ignaciano y castellano con apuntes gramaticales, 644 pp.; Cochabamba: Instituto Lingüístico de Verano, Ministerio de Educación y Cultura.

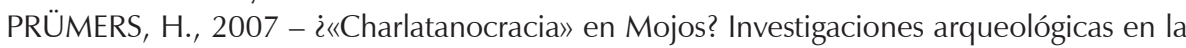
Loma Salvatierra, Beni, Bolivia. Boletín de arqueología PUCP, 11: 103-116.

QUEREJAZU LEWIS, R., 2008 - Trayectoria histórica y cultural de los trinitarios, 494 pp.; Cochabamba: Universidad Mayor de San Simón-Facultad de Arquitectura.

RIBERA PANIAGUA, J., 2009 - Clasificación bibliográfica sobre etnografía mojeña en los años 1669-1832. Geografía - Etnografía - Evangelización, 211 pp.; Trinidad: Sociedad de estudios geográficos e históricos del Beni. Memoria para postular a miembro de número.

SAITO, A., 2005 - Las misiones y la administración del documento: El caso de Mojos, siglos XVIII-XX. In: Usos del documento y cambios sociales en la historia de Bolivia (C. López Beltrán \& A. Saito, eds.): 27-72; Osaka: Nacional Museum of History.

SAITO, A., 2015 - Guerra y evangelización en las missiones jesuíticas de Moxos. Boletín Americanista, LXV (70): 35-56.

SOLíZ, V. de, 1906 [1635] - [Relación de Vasco de Solíz.] In: Consultas hechas á S.M. por Don Juan de Lizarazu, Presidente de Charcas, sobre su entrada á los Moxos ó Toros. In: Juicio de límites entre el Perú y Bolivia. Prueba peruana presentada al Gobierno de la República Argentina, t. IX, Mojos I (V. M. Maurtua, ed.): 182-186; Barcelona: Imprenta de los Hijos de G. M. Hernández.

SOTO, J. de, 1668 - Relacion de lo succedido en la Jornada de los Mojos. Año de 1667. La Plata, 30 de enero 1668. In: PERÚ 20: fo130r.-138v.; Roma: Archivum Romanum Societatis lesu (ARSI).

STERPIN, A., 1993 - La chasse aux scalps chez les Nivacle du Gran Chaco. Journal de la société des américanistes, 79 (1): 33-66.

TAYLOR, A. C., 1985 - L'art de la réduction. La guerre et les mécanismes de la différenciation tribale dans la culture jivaro. Journal de la société des américanistes, 71 (1): 159173.

TAYLOR, A. C., 1993 - Des fantômes stupéfiants : langage et croyance dans la pensée achuar. L'Homme, 33 (126): 429-447.

TAYLOR, A. C., 1994 - Les bons ennemis et les mauvais parents. Le traitement symbolique de l'alliance dans les rituels de chasse aux têtes des Shuar (Jivaro) de l'Équateur. In: Les complexités de I'alliance. IV. Économie, politique et fondements symboliques (F. Héritier-Augé \& É. Copet-Rougier, eds.): 73-105; París: Éditions des archives contemporaines (Ordres sociaux). 
VIVEIROS DE CASTRO, E., 1992 - From the enemy's point of view: humanity and divinity in an Amazonian society, 407 pp.; Chicago, Londres: University of Chicago Press. Traducción del portugués por C. V. Howard.

VIVEIROS DE CASTRO, E., 2012 - Immanence and fear. Stranger-events and subjects in Amazonía. HAU: Journal of ethnographic theory, 2 (1): 27-43. Traducción del portugués por D. Rodgers con I. Dulley. 